\title{
Distribution System Planning and Innovation for Distributed Energy Futures
}

\author{
Eric Martinot $^{1}$ • Lorenzo Kristov ${ }^{2}$ • J. David Erickson ${ }^{3}$
}

Published online: 25 April 2015

(C) Springer International Publishing AG 2015

\begin{abstract}
In the future, electric power distribution utilities will need to plan, operate and innovate in a variety of new ways to contend with the changing nature of electricity system resources and opportunities. A distributed energy future leads to changing paradigms, changing needs in planning and innovation by distribution utilities, and changing regulatory directions. The changing paradigm encompasses two-way power flows, local integration and balancing, functional control of distributed resources, the changing nature of the boundary between transmission and distribution systems, the changing nature of resources and customers, and new business models. Changing needs in planning and innovation include handling two-way reversible power flows; interconnecting storage and electric vehicles; controlling flexible-demand resources; distribution system monitoring, analysis and modeling; renewable energy output forecasting; smart inverters; and data networks, analysis, and storage. Examples of changing regulatory directions are seen in New York, California, and Australia.
\end{abstract}

Keywords Distributed generation - Power systems . Renewable energy integration - Smart grids · Electricity regulation

This article is part of the Topical Collection on Power Sector

Eric Martinot

contact@martinot.info

1 School of Management and Economics, Beijing Institute of Technology, 5 Zhongguancun South St., Beijing 100081, China

2 California Independent System Operator, 250 Outcropping Way, Folsom, CA 95630, USA

3 California Public Utilities Commission, 505 Van Ness Ave., San Francisco, CA 94102, USA

\section{Introduction}

Power systems are clearly evolving at accelerating rates. In recent years, a lot of attention in the literature has focused on ongoing and future changes in thinking about power system architecture, operation, and integration of distributed resources like renewable generation, energy storage, and demand-side flexibility (demand response). In addition, the integration of electric vehicle charging, and heating and cooling infrastructure (i.e., combined-heat-and-power plants, chillers, and thermal energy storage) with electric power systems represents another level of future integration. These distributed resources and integration opportunities are changing the nature of planning, operation and innovation for distribution systems in fundamental ways [1-10].

Historically, distribution systems have been planned around two main principles: forecasting changes in customer load and planning upgrades and extensions on that basis; and anticipating equipment replacement needs as equipment reaches the end of its useful life. These planning questions historically had to be addressed only for the purpose of passive one-way delivery of energy from the high-voltage transmission grid to the end-use customers. Distribution system design and planning was thus quite standard and changed little over the decades. Distribution utilities did not necessarily need to be innovators, just good forecasters and planners, and could focus primarily on safety and reliability $[11,12]$.

In the future, distribution utilities will need to plan, operate and innovate in a variety of new ways to contend with much higher penetrations of distributed energy resources, and consequent two-way power flows and added reliability challenges. Moreover, demand response, storage, smart inverters, micro-grids, and a host of other emerging technologies are appearing on the "customer side of the meter" in new ways, posing further challenges for planning and management. 
Distribution utilities will be required to monitor, collect, analyze, and use data in new ways, and will be required to analytically model their distribution systems to a degree far beyond current practice. And utilities will be required to use a wide variety of information and communication technologies to achieve the necessary integration of all of these elements.

Over the past several years, there has been a growing body of literature that addresses this new era of distribution system planning and innovation [13-24]. However, the literature is still far from being identifiable as a coherent body of work, and appears across several categories of research and practice. For example, "smart grid" literature is a subset of distribution system planning and innovation, and tends to focus more on the data and communication tools to enable and achieve various distribution system innovations, rather than starting from the broader planning, operational and innovation needs and functions themselves [25-29].

A distributed electric power future leads to: (a) changing paradigms; (b) changing needs in planning, operation and innovation by distribution utilities; and (c) changing regulatory directions. These three elements are each summarized in turn below.

\section{Changing Paradigms}

A new paradigm for thinking about the role and function of distribution utilities has been emerging in recent years. This new paradigm also considers the changing technical role of the distribution system itself, relative to the bulk power grid, in providing power-system services including reliability and flexibility.

A number of recent papers point to different aspects of this paradigm. For example, Kristov and De Martini [15] introduce the terms "integrated distributed electricity system" and "distribution system operator (DSO)" to denote, respectively, a new electric system paradigm and an expanded functional role for the distribution utility (see Table 1).

The changing paradigm encompasses at least seven main dimensions:

1. Maintaining reliable distribution system operation with two-way, multi-point, reversible power flows. As the volume and diversity of distributed resources increase, power flows at the distribution system level can become twodirectional. Unless accounted for in system design and operation, frequent reversals in power flow can have serious consequences in distribution system operation. In order for distribution utilities to properly manage distribution systems, they must implement voltage monitoring, telemetry, and real-time control of components like transformers in response to dynamically changing conditions. And they may also need to actively manage customer-side resources. All of these things represent first-time innovations for distribution utilities, as historically, systems have been designed only for one-way flows and no customerside control [25].

2. Integrating and balancing distributed resources and load at the distribution level in order to shape the load profile and peak demand as seen by the bulk power system at the transmission-distribution interface (T-D interface) substation. New approaches to distribution system integration can create "multi-function" distributed resources that provide services to the bulk power system beyond simply energy delivery. In addition, the system can attain the capability to manage resource variability locally and start to function with some degree of autonomy. Distribution system integration can present more "bounded and predictable" behavior to the bulk grid, with specific load characteristics and timing. To the degree to which this distribution-level integration results in a predicable (or even programmable) load curve, this can reduce the need for transmission and generation investments in bulk system flexibility, ramping, and reliability $[14,15]$.

Local self-balancing can occur at several geographical levels within a distribution system, for example, on an individual feeder, or at the level of a single (lowvoltage) distribution substation, or for everything connected to an entire distribution network below a single (high-voltage) transmission-distribution substation. At whatever level, the DSO starts to integrate and balance variable distributed generation, flexible and controllable loads (including electric vehicle charging), storage, and smart inverters capable of providing grid services, like balancing and ramping. Another emerging development is the possibility of creating local energy markets operated by the DSO, outside of the bulk-grid markets, through which local-distributed resources offer energy to local end-users (see New York REV case later in this paper), as well as grid services to the DSO, such as grid services to enable local self-balancing, or services to either shorten or eliminate outages caused by accidental events [16].

3. Functional control of distributed resources for purposes of providing real-time balancing and flexibility, as well as other services, such as reactive power and frequency control to the local or bulk grid. How can control of distributed resources provide flexibility? Today, distributed resources are seen and modeled by system operators predominantly as load or load modifiers (load reducers), not as generation. In the future, control of distributed resources can provide flexibility to the bulk grid, but there are many alternative frameworks for how this flexibility is controlled, and who receives economic value from the grid services provided. Do distributed resources participate in wholesale markets, either individually or aggregated by intermediaries? Does the TSO dispatch these resources, or does the DSO? If a 
Table 1 Future integrated distributed electricity system

Kristov and De Martini [15] point to future distribution system operators (DSOs) at the heart of a future "integrated distributed" electricity system. In this future system, a DSO is "a single entity [that] operates each local distribution area and is responsible for providing reliable real-time distribution service." And the DSO's operational responsibility for the local distribution area must encompass all activities required to maintain safe, reliable, efficient distribution service to customers and connected distributed energy resources (DER), as well as a stable interface with the transmission grid. This means the DSO must coordinate operations of the interconnected DER, micro-grids and self-optimizing customers, and schedule interchange with the TSO at the T-D interface. Such a system requires an integrated and coordinated operational paradigm that clearly delineates roles and responsibilities between the transmission system operator (TSO) and DSOs. In this new paradigm, Kristov and De Martini outline four basic functions that span across the TSO-DSO boundary:

1. Distributed reliability services support reliable real-time distribution system operations. The concept of "distributed reliability" is itself new. Kristov and De Martini define it as a "federated reliability paradigm" in which DSOs, and potentially micro-grids and self-optimizing customers, have responsibility and accountability for the reliable real-time operation of the respective electric systems under their operational control. Underlying this concept is the recognition that many types of DER and independent micro-grids will be capable of providing such services. Reliability services will be provided by diverse DER, according to their performance characteristics and capabilities, to the local distribution system to which they are connected. These services may be provided to the DSO via tariffs, bilateral contracts or other means, to enable the DSO to reliably operate the distribution system and manage variability at the T-D interface, and may also be provided to other entities across the distribution system, such as municipal utilities. The DSO's ability to use locally provided reliability services will enable it to maintain a more stable and predictable interchange with the TSO at the T-D interface, thereby relying less on the TSO to provide energy balancing and other real-time services, and even utilizing DER with appropriate performance capabilities to provide such services back to the TSO.

2. T-D interface reliability coordination ensures that DER-provided services are properly coordinated, scheduled and managed in real-time so that the TSO has predictability and assurance that DER committed to provide grid services will actually deliver those services across the distribution system to the T-D interface. The DSO must ensure that the DER providing reliability services don't have any conflicting service commitments, such as offering the same capacity to serve both the TSO and the DSO or another entity. This coordination also involves ensuring that DER dispatch (via direct control or economic signal) doesn't create detrimental effects on the local distribution system, and will require schedule and dispatch coordination at the T-D interface between the TSO and DSO. At a minimum, the DSO will likely be the best positioned entity to forecast net load in each local distribution area and net power flows across the T-D interface.

3. Energy transaction coordination across the T-D interface means that, at a minimum, the physical aspects (not the financial aspects) of energy transactions will need to be coordinated by the DSO. This does not mean that DSOs will operate balancing markets or dispatch wholesale-market resources, which can remain the sole responsibility of the TSO. The DSO will, however, need to coordinate with the TSO energy and capacity delivery schedules to ensure operational integrity of the distribution system.
Table 1 (continued)

4. Dispatch coordination is a possible extended model of a DSO with expanded functional responsibilities in addition to those above. In this model the DSO provides a single point of control on the distribution side of a T-D interface for the purpose of operational dispatch coordination of all DER in the local distribution area that intend to participate in wholesale energy and/or ancillary services markets under TSO control.

distribution-level resource wants to provide service to both the bulk system and the distribution system simultaneously, which entity has priority? How does the DER owner/ operator participate in any market-based dispatch of the DER? Are there a set of pre-approved autonomous-operating regimes? All of these questions face technical, economic, regulatory, and political issues that are just beginning to be explored by regulators and stakeholders $[14-17,30]$.

4. New ways of defining and managing the boundary between transmission and distribution (T-D interface) in terms of all the market, technical, service, and coordination functions necessary to reliably and optimally operate the whole power system. Historically, in vertically integrated monopoly utilities, there were operational and architectural differences between transmission and distribution systems, but their operation and planning were performed by a single entity, whether public or private. Then, in jurisdictions that restructured their power sectors in the 1990s and 2000 s, the operational and planning functions of the transmission system were assigned to newly created transmission system operators (TSOs). ${ }^{1}$ From an electrical perspective, there was effectively no change: power still flowed from central station generation over the transmission network, then across the T-D interface substations into distribution circuits that passively transmitted energy one way to end-use customers. The significant changes of past restructuring were largely organizational, with the new independent TSOs becoming operators of both the highvoltage grid and the wholesale markets through which buyers and sellers of bulk power and capacity transacted. In some areas, the T-D interface also became a more significant regulatory boundary; in the United States, for example, transmission and wholesale markets are regulated by the federal government (FERC), while distribution systems and retail markets, where they exist, are regulated by state governments. But now, with the accelerating proliferation of distributed resources, that boundary is blurred and is opening economic and public policy debates as to the

\footnotetext{
${ }^{1}$ Transmission system operators may be abbreviated as "TSOs", "ISOs" or "RTOs" depending on jurisdiction. This paper uses "TSOs," although the functions of such organizations also differs across different jurisdictions.
} 
best market, regulatory, and technical control structures and ways to develop power systems at least cost to consumers [14-16, 20, 25].

5. The changing nature of resources. "Resources" traditionally were large power plants. In the future, "resources" will increasingly encompass many demand-side measures, like automatic demand response and dynamic pricing, which can be viewed in comparison with (and in market competition with) the historically traditional resources. Combined-heat-and-power plants will be combined with heat storage to allow very flexible electricity output while still keeping heat supply constant. Air conditioners (chillers) with thermal storage will be able to shift their demand over a several hour period upon command. All of these can be considered "resources" $[9,10$, 31-34].

6. The changing nature of customers. Similarly, "customers" traditionally meant end-users or consumers of electricity typically located at an end point of a distribution circuit and wholly dependent on that circuit and on the upstream transmission system and central generation to supply their needs. In the future, the definition of customers must expand in at least two ways. First, many end-users are installing supply and storage facilities "behind the meter" on their own premises and, as a result, are able to alternately consume energy from and supply energy to the grid. The term "prosumers" has become a widely used term to express the fact that the same entity may be both a consumer and a producer, at different times. Indeed, many such "prosumers" are becoming able to provide the majority, or even all, of their own power needs (although likely still relying on the grid for back-up). Second, distributed energy resources themselves must be thought of as "customers" of distribution utilities, since these resources rely on DSOs to operate the distribution system in a manner that allows the distributed resources to earn revenue from selling (surplus) energy, and/or from selling grid support, like balancing or ramping. From the perspective of the DSO, the "customers" that depend on and pay for its distribution-grid services will comprise a much larger and diverse category in the future.

7. New utility business models and the changing nature of distribution utilities themselves. New business models that take advantage of the preceding dimensions of a paradigm change will also be required for utilities to fully embrace the changes, or even to survive as profitable entities. Many examples around the world can be found of such new and emerging business models. And distribution utilities themselves are evolving into a much more diverse array of configurations and structures, which are starting to be called names like "micro-utilities," "(local) energy service providers," and "smart integrators" [27, $35,36]$.

\section{Changing Needs in Planning, Operation and Innovation}

Eight of the most significant categories of planning, operation and innovation needed by distribution utilities in the future are outlined in this section.

1. Handling two-way, reversible power flows. This requires real-time monitoring of voltages along distribution lines, something that distribution utilities have not needed to do historically, and then adjusting the distribution system (primarily through adjusting transformers) to achieve the correct voltages with two-way power flows. This also requires changing the band of acceptable operating voltages, so as to allow some voltage "reserve" in case of voltage rise from distributed generation. Traditionally, utilities have operated distribution grids almost "blindly", without any data measurement of system conditions. In the future with two-way power flows, utilities will have to operate not only with "sight" but also "foresight" [17, 20]. Palensky and Kupzog [25] write (p. 207): “Given an appropriate automation infrastructure enabling remote access to voltage and reactive power measurements, a distributed control system can be designed that not only keeps voltage in its limits but also optimizes other aspects, such as maximum renewable power utilization and/or minimal distribution losses."

2. Interconnecting storage. The interconnection of distributed storage is partly a technical issue - how to model the operation of a storage resource to ensure that the distribution system is technically able to support the physical interconnection. This requires understanding its programmed operating regime in terms of when and whether charging and discharging coincides with distribution system peaks. For example, in California, current interconnection requirements under "Rule 21 " specify that storage must be treated like a load in calculating the worst-case situation, which then carries over to specifying the necessary distribution system upgrades to accommodate that storage. But a "worst-case" situation would typically be at peak periods of the day, while under plausible operating regimes, storage during peak periods would not be operated as a load, but rather operated as a generator (to take advantage of peak pricing). If operated only as a generator at peak periods, interconnection costs may be lower, resulting in economic savings. But the planning framework under Rule 21 is not yet adapted to such considerations [37, 38].

Storage interconnection also represents a broader market design and regulatory issue. The first regulatory problem is how to define distributed storage for regulatory purposes. Is it generation? Is it load? Is it both? Is it dispatchable? What tariffs should apply? Should the definition and regulatory treatment be different if the storage is 
used only to buy and sell from the grid (with no selfconsumption of stored energy as load), or if the storage is also used for internal consumption purposes (i.e., storing local generation or purchased power for later consumption)? Distribution system planning will depend on the answers to such questions.

3. Interconnecting electric vehicles. Electric vehicles may be considered a unique category of energy storage, and discussions are underway in many jurisdictions about how to treat electric vehicles - as load, as demand response, or as storage. Interconnection of EV charging may or may not follow the same interconnection rules and tariffs as conventional battery energy storage would. As a unique resource, electric vehicles may need different tariffs and rules. For example, the non-fixed geographic location of electric vehicles when connected to the distribution system creates challenges in terms of providing dependable storage capacity or energy. Modeling the behavior of large numbers of electric vehicles will require more experience with how operators use their vehicles, and where and when they connect to the distribution system [27].

4. Controlling flexible-demand resources ("demand response"). Demand response has great potential to provide flexibility to future power systems $[9,10,31]$. But virtually all demand response takes place physically at the distribution level. What types of control for DR resources will exist? Will DR be controlled by the customer in response to dynamic prices and/or system conditions? Or will it be controlled by the distribution utility? Or by the ISO/TSO? Or by a third-party aggregator? Distribution system planning will depend on the answers to such questions, and the acceptable range of possibilities as determined by regulators.

5. Distribution system analysis and modeling. Distribution utilities will need to undertake new levels of analysis and modeling of their distribution systems, far beyond their traditional practice. In the words of De Martini [14]: "Analysis today requires both the traditional power engineering analysis as well as an assessment of the random variability and power flows across a distribution system. Such an analysis would include real and reactive power flows under a variety of planned and unplanned situations across a distribution system, not just a single feeder... Evolution to a more network centric model for a distribution system to enable bi-directional power flow underscores the need for a fundamental shift in planning analyses." This can include, for example:

- Modeling the technical distribution system, including real-time state estimation based on real-time data, to enable rapid interconnection studies in response to customer requests for interconnection and to manage grid operation.
- Conducting sophisticated demand forecasting, including using stochastic models, metering data, customer surveys, and bottom-up aggregation of different load categories and parameters.

- Calculating and applying "locational value" of resources. "Locational value" takes into account where the resource is located within a distribution system and how the resource at that location can reduce future distribution system investment needs (i.e., postponing or avoiding network upgrades based on the presence of distributed resources) [47].

- Calculating and applying distributed resource value other than locational value. New metrics and methodologies for calculating a variety of economic values of distributed resources.

- Calculating "integration capacity." This analysis shows how much DER can be integrated in different locations of the distribution network.

6. Renewable energy output forecasting using day-ahead and real-time weather forecasting. Distribution utilities will need to forecast renewable generation on their systems in the same way that TSOs do, to aid in balancing supply and demand locally, and in managing power flows within the distribution system.

7. Smart-inverter practices, codes and standards, and control. Smart inverters can provide voltage and reactive power support to the distribution grid that can mitigate over-voltage problems from distributed generation and increase the integration capacity of distributed generation $[39,40]$. Smart inverters can also provide grid reliability service and flexibility, by altering their output in real-time in response to system needs for ramping. And smart inverters can potentially provide a range of other advanced grid services like islanding operation and black start capability. One key consideration is who will control these smart inverters, the owner of the distributed resource, the DSO, or potential third-party aggregators? Another consideration is the optimal arrangement of controls in a given distribution system area for local voltage and reactive power support, in terms of how much is provided by smart inverters (and whether all DER needs to have smart inverters) versus how much is provided by DSO-owned equipment. California is the only state in the U.S. to have so far adopted smart inverter standards (which so far are for voltage and reactive power support only) [41].

8. Data networks, analysis, and storage. There is a very broad need to design the communications and data management infrastructure to support the operational requirements described in this section. For example, the need for distribution-grid monitoring and state estimation from a combination of customer meters, voltage and power flow line monitoring, and/or transformer monitoring. And the 
need to process and use the information in variety of ways, for example establishing real-time voltage control set-points for distributed energy resources, and day-ahead forecasting and optimization of necessary control actions.

A number of distribution utilities around the world are actively engaged in moving into this new paradigm of distribution planning and innovation. Unfortunately, there are few case studies in the literature as yet. One innovative case is EWE Netz in Germany; see Table 2.

\section{Changing Regulatory Efforts Aimed at Distribution Systems of the Future}

Regulatory frameworks for distribution utilities vary greatly around the world, but most share a common feature: as "natural monopolies," distribution utilities get a regulated rate of return on their investments in necessary distribution system upgrades. Investment toward new "integrated" paradigms is not necessarily possible under existing regulatory frameworks. For example, distribution utilities may not be able to include research and development costs in their regulated revenue base. Thus, an important part of the literature also covers policy changes that may be necessary to bring about the planning and innovation discussed in this paper; see for example Newcomb et al. [22] and Wiedman and Beach [23].

\section{Table 2 EWE Netz}

EWE Netz is a distribution utility serving north-west Germany, based in Oldenburg. EWE has a high penetration of renewable energy on its grid; in 2013, $70 \%$ of the power consumption by EWE's customers came from local renewable energy sources. EWE is already doing a number of things to integrate and balance renewables on the distribution grid that go well beyond current practice of most distribution utilities, and also go beyond current regulatory requirements for DSOs in Germany: (a) EWE has its own weather/renewable energy output forecasting system. (b) EWE does its own curtailment orders based on local grid capacities. (c) Voltage monitoring in certain areas, along with voltage stabilization measures. All medium-voltage distribution stations have been integrated into a fiber-optic network. (d) EWE has developed and maintains a real-time model of the whole distribution grid. It can use this model to approve interconnections of new renewable capacity in real-time. (e) Research and grid planning are done at a more sophisticated level than previously [42].

EWE also conducted a number of "eTelligence" pilot projects during 2010-2012 that included (a) residential demand response; (b) "virtual power plants" consisting of distributed renewables and demand response from refrigerated warehouses, for local scheduling and balancing of renewables. (The idea was to create a power plant that could be reliably scheduled and operated, with local balancing of resources.) (c) a local energy marketplace for local buying and selling, with energy traded in 1-h and 15-min contracts, including wind farms, solar PV systems, combined-heat-and-power plants, and on the demand side, electric vehicles and refrigerated warehouses [43].
Three notable examples follow of regulatory frameworks that have evolved in recent years to explicitly address the future needs of distribution planning and innovation. These examples are all of jurisdictions facing increasing shares of distributed energy resources, particularly solar power. In the future, many regulatory efforts across the world could be driven by the urgency of the needs discussed in this paper, as the share of distributed resources in specific jurisdictions grows to higher levels.

New York: New York started a "Reforming the Energy Vision" initiative in 2013 that envisions a "distributed system platform" (DSP) for integrating distributed resources. The platform will allow energy from distributed resources to be tracked, forecast, and traded within the distribution system. The vision includes several elements, such as: retail-level energy markets; opportunities for new retail-level energy services; market-based distributed energy resource (DER) contribution to system balancing, flexibility and reliability; demand management on a dayahead or real-time basis; expanded access to system information by customers and DER providers to help them calculate time-based and location-based economic values; demand-response tariffs, including tariffs for storage; regulatory oversight of DER providers; and limits on ownership of DERs by distribution utilities themselves. The vision is that this new platform will facilitate widespread deployment of DERs, two-way power flows, advanced communications, distribution system monitoring and management systems, and automated controls of energy sources and loads. And the DSP will coordinate its retail markets with the New York ISO's wholesale markets; for example the ISO could accept demand-reduction bids by the DSP in the wholesale market [44-46]. California: Assembly Bill (AB) 327 passed the California Legislature in 2013. The bill amends Public Utilities Code Section (§) 769 and requires utilities to submit Distribution Resource Plans (DRPs) that recognize, among other things, the need for investment in upgrading the distribution system to integrate costeffective distributed generation, and for actively identifying barriers to the deployment of distributed generation. Such barriers include adequate safety standards related to technology or operation of the distribution circuit, for example. Section 769, together with a new CPUC regulatory proceeding on this subject that opened in August 2014, constitute a major new push in California to address distribution system planning and innovation in the future, and for addressing the needs of balancing and integrating distributed renewables in the most effective manner, such that distribution systems themselves contribute to overall power-system flexibility and reliability [47-49]. 
Australia: In 2013, Australia enacted a "regulatory investment test for distribution" that requires all DSOs to assess "non-wire" alternatives such as demand management and distributed generation when contemplating any network-upgrade project greater than A $\$ 1$ million. DSOs in Australia are also required by national policy to produce "Distribution Planning Annual Reports" with 5-year planning horizons. One such plan is by the DSO for the state of South Australia, SA Power Network, which has developed a 15-year "Future Operating Model 2013-2028" in which it presents its vision of its distribution network in the next 15 years. This DSO forecasts expected penetration of DER over the next 15 years, including customer adoption of DR and other demand-side measures, as well as penetration of electric vehicle charging, and anticipating the need to manage two-way power flows and integrate the levels of DER expected $[50,51]$.

\section{Conclusion: Toward a More Coherent Literature}

The literature on distribution system planning and innovation is widely diverse and scattered among several subject categories. These include "distributed generation," "power systems of the future," "smart grids," "integrated grids," and several others. In the future, a more cohesive and readily identifiable body of literature should emerge that addresses the paradigm changes, needs for planning and innovation, business models, regulatory models and approaches, and real-world cases of actual planning and innovation at the distribution level, as pointed to and suggested in this paper.

Acknowledgements This paper benefited from the research contributions of Romain Zissler, and from the support of the Japan Renewable Energy Foundation and the Institute for Advanced Sustainability Studies.

\section{References}

1. NREL. "Power systems of the future." NREL/TP-6A20-62611. Golden, CO.; 2015.

2. NREL. "Flexibility in 21 st century power systems." NREL Report 61721. Golden, CO.; 2014.

3. Volk D. Electricity networks: infrastructure and operations. IEA Insight Paper, OECD/IEA, Paris; 2013.

4. International Energy Agency, Renewable Energy Technology Deployment (RETD). 2014. "RE-integration: integration of variable renewable electricity sources in electricity systems - lessons learnt and guidelines." Paris: OECD, forthcoming.

5. International Energy Agency. The power of transformation — wind, sun and the economics of flexible power systems. Paris: OECD; 2014.

6. International Energy Agency. Energy technology perspectives 2014. Paris: OECD/IEA; 2014.
7. Jones L. Renewable energy integration: practical management of variability, uncertainty, and flexibility in power grids. London: Elsevier; 2014.

8. Denholm P, Jorgenson J, Hummon M, Jenkin T, Palchak D, Kirby $\mathrm{B}$, Ma O, O'Malley $\mathrm{M}$. The value of energy storage for grid applications. Golden, CO: NREL.; 2013, 45 pp.

9. Wikler G, Martin P, Shen B, Ghatikar G, Chun CN, Dudley JH. Addressing energy demand through demand response: international experiences and practices. Berkeley: LBNL; 2012. 38 pp.

10. Watson DS, Matson NE, Page J, Kiliccote S, Piette MA, Corfee K, et al. Fast automated demand response to enable the integration of renewable resources. Berkeley: LBNL; 2012. 43 pp.

11. Gómez T. "Electricity distribution", in Regulation of the power sector, Pérez-Arriaga, ed., pp. 199-250. London: Springer; 2013.

12. Willis HL. Power distribution planning reference book. New York: Marcel Dekker; 2004.

13. Borbely AM, JF Kreider, eds. Distributed generation: the power paradigm for the new millennium. CRC Press; 2001, 400 pp.

14. DeMartini P. "More than smart: a framework to make the distribution grid more open, efficient, and resilient." Pasadena: Resnick Institute, California Institute of Technology; 2014, 28 pp.

15. Kristov L, DeMartini P. " 21 st century electric distribution system operations." Folsom: California Independent System Operator; 2014, $11 \mathrm{pp}$.

16. Electric Power Research Institute. "The integrated grid: realizing the full value of central and distributed energy resources." Palo Alto, CA; 2014. 44 pp.

17. Electric Power Research Institute. "Integrating smart distributed energy resources with distribution management systems." Palo Alto, CA; 2012. 13 pp.

18. Union of the Electricity Industry. "Active distribution system management: a key tool for the smooth integration of distributed generation." Brussels: Eurelectric; 2013, 53 pp.

19. PV GRID. "Prioritisation of technical solutions available for the integration of PV into the distribution grid." Brussels; 2013.

20. Electric Power Research Institute. Distributed energy resources and management of future distribution. Palo Alto, CA; 2010, 142 pp.

21. Bollen $\mathrm{MH}$, Hassen F. Integration of distributed generation in the power system. IEEE Press Series on Power Engineering; 2011. $524 \mathrm{pp}$.

22. Newcomb J, Lacy V, Hansen L, Bell M. "Distributed energy resources: policy implications of decentralization." Electr J. 2013;26(8):65-87.

23. Wiedman J, Beach T. "Distributed generation policy: encouraging generation on both sides of the meter." Electr J. 2013;26(8):88108.

24. Institute for Electric Innovation. Innovations across the grid: partnerships transforming the power sector. Washington DC: Edison Foundation; 2014, 275 pp.

25. Palensky P, Kupzog F. "Smart grids." Annu Rev Environ Resour. 2013;38:201-36.

26. International Energy Agency. Technology roadmap: smart grids. Paris; 2011, 52 pp.

27. Fox-Penner P. Smart power: climate change, the smart grid and the future of electric utilities. Washington DC: Island Press; 2010.

28. Komor P, Hoke A, Kempener R. "Seven steps to a smarter grid." Electr J. 2014;27(2):61-7.

29. Kempener R, Komor P, Hoke A. Smart grids and renewables: a guide for effective deployment. Bonn: International Renewable Energy Agency (IRENA); 2013. 44pp.

30. North American Electricity Reliability Corporation. IVGTF task team 1-8, potential bulk system reliability impacts of distributed resources. Atlanta; 2011.

31. Lazar J. "Teaching the duck to fly." Montpellier, VT: Regulatory Assistance Project; 2014. 25 pp. 
32. Dissemination strategy on electricity balancing for large scale integration of renewable energy (DESIRE). Project Summary and Achievements; 2015. http://desire.iwes.fraunhofer.de/results.htm

33. Agora Energiewende. "Electricity storage in the german energy transition." Berlin; 2014. 26 pp. [Has section on thermal energy storage.]

34. Agora Energiewende. "12 insights on Germany's energiewende." Berlin; 2013. 36 pp.

35. Lehr RL. "New utility business models: utility and regulatory models for the modern era." Electr J. 2013;26(8):35-53.

36. Sioshansi FP. "Why the time has arrived to rethink the electric business model." Electr J. 2012;25(7):65-74.

37. California Public Utilities Commission. "Interconnection (Rule 21)"; 2015. http://www.cpuc.ca.gov/PUC/energy/rule21.htm

38. Elliott, R. "The integration of distribution level generation and storage into the grid: problems and solutions; grid planning and reliability policy paper." San Francisco, CA: California Public Utilities Commission, Energy Division; 2014. http://www.cpuc.ca.gov/NR/ rdonlyres/DD76B018-7203-4864-B391-7DE680BA9E68/0/ ReportLatestAugust2014Version.pdf

39. Electric Power Research Institute. "Common functions for smart inverters, Version 2," Palo Alto, CA; 2012. Report 1026809.

40. Electric Power Research Institute. "Grid impacts of distributed generation with advanced inverter functions: hosting capacity of large-scale PV using smart inverters," Palo Alto, CA; 2013. Report 3002001246.

41. California Public Utilities Commission. 2014. "Order instituting rulemaking on the commission's own motion to improve distribution level interconnection rules and regulations for certain classes of electric generators and electric storage resources.” Rulemaking R. 11-09-011, Decision 14-12-035 December 18, 2014, "Interim decision adopting revisions to electric tariff Rule 21...to require 'smart' inverters."

42. Markus Merkel, personal communication, June 30, 2014.

43. EWE AG. "eTelligence final report." Oldenburg, Germany; 2013.

44. New York Department of Public Service. "Reforming the energy vision (REV)." Staff paper. Albany, NY; 2014.

45. New York Department of Public Service. "Developing the REV market in New York: DPS staff straw proposal on track one issues." Albany, NY; 2014.

46. Electricity Currents, "New York state embarks on bold new vision." Electricity J 27(6): 1-3.

47. California Public Utilities Commission. 2014. "Order instituting rulemaking regarding policies, procedures and rules for development of distribution resources plans persuant to public utilities code Section 769." Rulemaking R. 14-08-013 adopted August 14, 2014.

48. Electricity Currents, "California confronts changing role of distribution." The Electricity Journal 27(8): 1;4-7.

49. California Assembly. Assembly Bill 327, Electricity: natural gas: rates: net energy metering: California renewables portfolio standard program. Sacramento, CA; 2013.

50. Australian Energy Regulator. Regulatory investment test for distribution (RIT-D) and application guidelines; 2013. http://www.aer. gov.au/node/19146

51. SA Power Network. "Future operating model 2013-2028"; 2013. http://talkingpower.com.au/wordpress/wp-content/uploads/SAPower-Networks-Future-Operating-Model-2013\%E2\%80\% 932028.pdf 